UCRL-CR- -104934

DE91 000814

\title{
PHOTOCONDUCTIVITY OF ACTIVATED
}

CARBON FIBERS

K. Kuriyama

M. S. Dresselhaus

MIT

Cambridge, Massachusetts

Whand

Jath

OCT 151990

August 1990

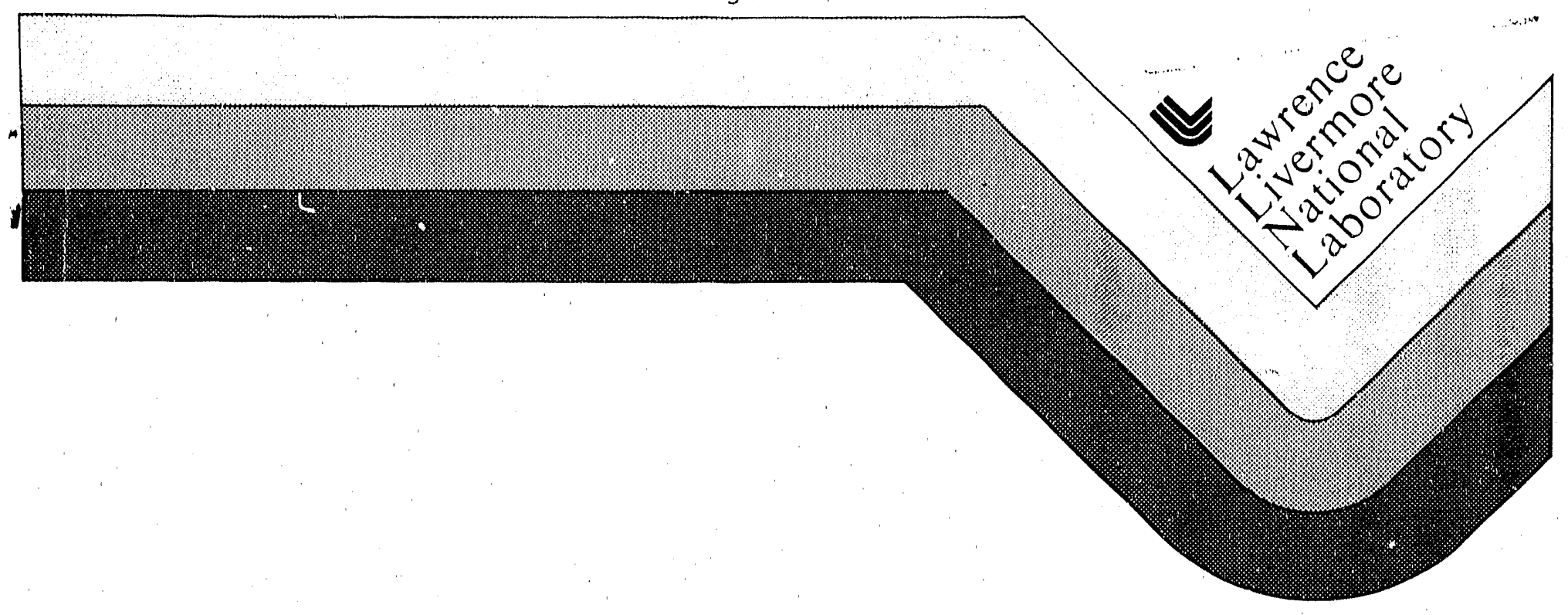


DISCIAIMFR

Work performed under the atuspices of the 1/.s. Department of binergy by Jawrence Livermore Natbonal Iaboratory under contract number W-74(05-fiN (;-48.

This document was prepared as an account of work sponsored by an agency of the llated States Covernment. Neither the Inited Sitates Government nor the Iniversity of Cillifornio nor any of their employees, make's any warranty express or implied, or assumes any legal liability or responsibility for the accuracy, completeness, or usefulness of uny information, upparatus, product, or process disclessed, or represents that its use would not infringe privately awned rights. Reference herein to any specific commenercial products, process, ur service by trude name, trademark, manufaclurer, or otherwise, does not nee'essurily constitute or imply lls endorsement, recommendation, or favoring by the I nited Situles covernment or the llaversity of Culiforniat. The views and opingoms of anthors expressed hercin do not necessarily state or reflect tlase of the lenited States (iovermment or the Iniversity of callfornia, and shall not be used for udvertising or produet endorsement porposes. 


\title{
Photoconductivity of Activated Carbon Fibers
}

\author{
K.Kuriyama ${ }^{+}$and M.S.Dresselhaus \\ Department of Electrical. Engineering and Physics \\ Massachusetts Institute of Technology, Cambridge, Massachusetts 02139
}

The photoconductivity is measured on a high-surface-area disordered carbon material, namely activated carbon fibers, to investigate thel.r electronic properties. Measurements of decay time, recomblnation kinetics and temperature dependence of the photoconductivity generally reflect the electronic properties of a material. The material studied in this paper is a highly disordered carbon derived from a phenolic precursor, having a huge specific. surface area of $1000-2000 \mathrm{~m}^{2} / \mathrm{g}$. Our preliminary thermopower measurements suggest that this carbon material is a p-type semiconductor with an amorphous-like microstructure. The intrinsic electrical conductivity, on the order of $20 \mathrm{~S} / \mathrm{cm}$ at room temperature, increases with increasing temperature in the range 30-290K. In contrast with the intrinsic conductivity, the photoconductivity in vacuum decreases with increasing temperature. The recombination kinetics changes from a monomolecular process at room temperature to a bimolecular process at low temperatures. The observed decay time of the photoconductivity is $\simeq 0.3 \mathrm{sec}$. The magnitude of the photoconductive signal was reduced by a factor of ten when the sample was exposed to air. The intrinsic carrier density and the activation energy for conduction are estinated to be $\approx 10^{21} / \mathrm{cm}^{3}$ and $\simeq 20 \mathrm{mev}$, respectively. The majority of the induced photocarriers and of the intrinsic carriers are trapped, resulting in the long decay time of the photoconductivity and the positive temperature dependence of the conductivity.

\section{Introduction}

Study of the electronic properties of disordered systems is currently an area of active interest. In the case of carbon materials, interesting phenomena have heen observed in some disordered carbons, such as Saran carbon 
rods(in terms of their conductivity[1]), active carbon rods(in terms of their resistivity $[2,3]$ ), evaporated carbon films (in terms of their resistivity $[4,5]$, photoconductivity [6], optical absorption edge [7], adsorption [8,9] and ESR [10]), anthracite carbon powders (in terms of their electrical properties [11]), glassy carbons [12-14] and others [15-20]. A series of systematic investigations on the electronic properties of varlous types of carbon matertals have been carried out by Mrozowskil[21-27].

Activated carbon fibers(ACFs) are expected to show electronic behavior characteristic of disordered systems, since ACF's are a highly disordered carbon material. As shown in a B.E.'T measurenent of other activated carbon materials[1], every second atom can be a surface atom that has a dangling bond. Thus activated carbon is regarded as a good material for research on strongly disordered systens. However, few electronic properties of ACFs have been reported, though their adsorption properties have been extensively investigated [28-41]. 'The adsorption rate of the ACF's is 100-1000 times faster than granular-type activated carbons and the adsorption capacity is ten times greater than that for the granular-type[33]. An electric double layer capacttor [34] is an example of an application taking advantage of the huge specific surface area of $A C F$.

The fibers of the present study are derived from phenol, one of four precursors used to prepare $\Lambda C F ' s$ : $\operatorname{PAN}[28,29]$, cellulose[30], pi.tch[31] or phenol $[32,33]$. To prepare the ACF's, these precursors are activated at temperatures $1100-1400 \mathrm{~K}$ in $\mathrm{O}_{2}, \mathrm{H}_{2} \mathrm{O}, \mathrm{CO}_{2}$ or other oxidizing atmospheres [34-38]. In contrast with usual heat treatments, the consequence of this heat treatment is to form more disorder in the matertal. 'The spectific surface area is controlled by changing the temperature and the time for the activation process. The maximum spectfic surface area is about $2300 \mathrm{~m}^{2} / \mathrm{g}$ in cormercial activated carbon fibers [33]. Among these ACF's, the phenol-derived flbers studied in this paper have a relatively high strength, a large specific surface area and require a stmple process for activation[33]. They have a diameter of around $10 \mu$, a conductivity of the order $20 \mathrm{~s} / \mathrm{cm}$ at room temperature and a specific surface area in the range $1000-2000 \mathrm{~m}^{2} / \mathrm{g}$. 
In this work, photoconductivity was used as one of the main techniques to characterize the ACF's, since photoconductive measurements have several advantages over other characterization techniques. If the density of photocarriers is known, the density of intrinsic carriers can be estimated based on the recomblnation kinetics. The existence of trap states is inferred by the observation of decay time. General concepts are described in details in several monographs on photoconductivity and related phenomena[42-44]. Thus photoconductive data give information necessary to describe the electronic properties of the material.

For ACFs, photoconductive measurements are particularly useful as a characterization technique for the following reasons. Measurement of the Hall effect, which is usually a useful technique to detennine the type of carriers and their density, is not feasible because of the very small diameter of the ACFs. Even if the measurement were possible, good data would not be expected because the mobllity in such a disordered material should be very small. Because of the high degree of disorder of these fibers, other measurement techniques 1.ke Raman scat ering, magnetoresistance and themoelectric power give only qualitative com arisons anong the fibers.

In this paper, we firstly report the results of the conductivity and the photoconductivity measurements of the activated carbon fibers. Then the conduction mechantsm is discussed based on the temperature dependence. The long decay time of the photoconductivity contributes to the discussion as evidence of a hitgh density of trap states. 'The change in the recombination k.tnetics supports an argument that the conductivity increase is not a thermal. effect but a photoeffect. In the final section, we quantitatively fit the conductivity data to functional forms approprdate to consider the conduction mechanisms.

\section{Sarmples and Experimental Details}

A single phenol-derived activated carbon fiber (supplied by Kuraray Chemical Co.), with properties listed in 'I'able 1[33], is mounted on a mica substrate 
for conductivity measurements. The specific surface area of these fibers is derived from the last two digits of the fiber, name when multiplied by 100 in units of $\mathrm{m}^{2} / \mathrm{g}$ (see Table 1). The mica substrate was set on a copper heat sink that was suspended onto a cryo-stage of an Adr products cryogenics closed cycle He refrigerator (see Fig.1). To measure the sample temperature, a themometer was mounted on the opposite side of the copper heat sink. Electrical contact to the fibers was made with silver paint and four $0.5 \mathrm{~mm}$ diameter copper wires were thus attached for electrical contacts. A dc fourteminal method was used for the conductivity measurements with a congtant $1 \mu \mathrm{A}$ or $10 \mu \mathrm{A}$ current source. Ihe effect of the temperature rise due to Joule heating was negligible because the measurements showed the same resistivity at

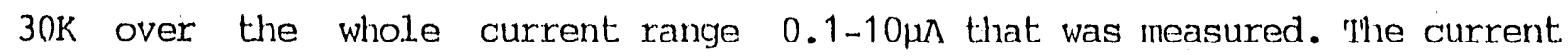
direction was reversed during the measurements to check for possible thermoelectric effects in the contacts.

The inside of the system was purnped down to $10^{-3}$ Torr at room temperature to reduce the effects of gas adsorption, since in a preliminary measurement a remarkable decrease in photoconductivity was observed for ACF's exposed to air. In air, the room temperature photoconductivity diminished by a factor of at least 10, compared to vacuum, although the intrinsic conductivity showed almost. no change between exposure to air or vacuurn. We interpret this result to indicate that the adsorption of gas molecules interacts with localized recombination centers and accelerates the recombination process, resulting in a decrease in the photocarrier lifetime. 'Ihis adsorption seems to be a physisorption process because the change tn the photoconductivity was observed to be reversible. Effects of oxygen and water vapor have been investigated in terms of gas adsorption on carbon materials $[2,3,8,9]$, where the intrinsic resistivity generally increased as a result of adsorption. In our experiments, water vapor is the most probable gas which changes the photoconductivity of the ACFs reversibly at room tenperature because reversible physisorption ustially occurs at temperatures below the bolling point of the adsorbates. Besides that, the effect of nitrogen is known to be negligible and oxygen is known to cause an irreverstble chemisorption at room temperature[8]. On the 
other hand, a change in the intrinstc resistivity was observed when a fiber was baked in air at around $300^{\circ} \mathrm{C}$. Ihe resistivity decreased $10-15 \%$ as a result of the baking and the rom temperature resistivity slowly returned to the initial value after exposure to air for one day. Thus the chemisorption of oxygen, which is not removed by punping down, is indicated to take place in the ACFs. Our experimental results therefore show some effects relevant to oxygen adsorption or surface oxidization.

Scanning electron microscopy(SEM) was used to determine the fiber dtameters and to observe the macrostructure of the fibers. The SEM results of Fig.2. for FR12, which has a speciflc surface are of $1200 \mathrm{~m}^{2} / \mathrm{g}$, show macroscoptc pores in the ACF's with openings of about $500 \AA$. Besides the macroscopic pores, the ACFs have microscopic pores with mean radil ilsted in Table 1 (obtained by the water vapor adsorption method (33]). As seen in F'Ig.2, the fibers have a rather regular round cross section and a smooth surface.

The diffraction pattern for $\mathrm{ACFs}(\mathrm{Fig} .3)$ is broad, indicating an amorphouslike microstructure. An estimate for $L_{C}$ of about $10 \AA$ (about three interlayer spacings, about the same length as for Saran carbon[1]), was obtained from the linewidth of the (002) X-ray diffraction line for phenol-derived ACF's with a spectific surface are of $1200 \mathrm{~m}^{2} / \mathrm{g}$.

We determined the dominant conduction type as p-type at room temperature by a rough measurement of the themoelectric power, which was found to be sinall. The high temperature terminal in this measurement showed a negative potential(1.e., carrier type is positive) and the thermoelectric power was found to be about $1.7 \mu \mathrm{V} / \mathrm{K}$ at room temperature. Highly disordered carbon matertals are known to be usually p-type $[45,46]$.

In the photoconductive measurements, an Ar ton laser beam (488n wavelength) with a 2 mm spot size and with $10 \mathrm{~mW}$ power was focused onto an entire ACF (1mm long, $10 \mu$ diameter) through focusing optics and a quartz window(see Fig.1). As shown in the figure, the beam covered the entire fiber, including a $1 \mathrm{~mm}$ interval between the two electrodes. I'he laser power was varied in the range $1-40 \mathrm{~mW}$ at each temperature $25,100,200$ and $290 \mathrm{~K}$ to determine the recombination kinetics. The number of incident photons on a filber, for example in the case 
of $10 \mathrm{mw}$ Incident laser power, was on the order of $10^{14} / \mathrm{sec}$.

\section{Results and Analysis}

A. Intrinsic conductivity

In this work, we use the term intrinsic conductivity to refer to the conductivity in the absence of light(dark current) and the term intrinsic carriers is used to denote the carriers present in the absence of the light excitation. In the measurements of the temperature dependence of the intrinsic conductivity $\sigma(T)$, a semiconductor-11ke positive temperature dependence for $\sigma(\mathrm{T})$ is found(see Fig.4). Ihis kind of temperature dependence is also observed In other disordered carbons $[2,4,5,12,14,19,20,47,48]$. Table 2 shows room temperature conductivities of the ACF's and other disordered carbon materials. The magnitude of this conductivity and its temperature-dependence are simdlar to those of Saran carbon[1], active carbon rods [3], glassy carbons heat treated at about 1000-1100K[12] and anthracene chars [47]. 'The magnitude of the conductivity is higher than that of evaporated carbon filims[5] but lower than that of vapor-grown carbon fibers [49] and PAN-based fihers[50].

One of the features of interest in Fig.4 is the nearly linear temperature dependence of the conductivity for all ACF's in the studied temperature range. on the other hand, the slight departure from linearity gives information on the conduction mechantsin discussed in section IV. The dominant conduction mechantsm in this material seems to be a thermal activation process in the studied temperature range. However at low temperatures (below $\simeq 40 \mathrm{~K}$ ), the conduction due to the thermal activation will be small and then hopping of carriers from one localized state to another(variable range hopping) will be dominant[51]. In this case, more disorder facilitates the hopping of carriers as the defect state density near the Fenni level increases and the defects involved in the hopping process come closer to one another. Looking at the low teniperature regime in Fig.4, the fibers with more disorder(1.e., more specific surface area) have the higher conductivities. On the other hand, at high 
temperatures the themal activation process will be clominant, as the carriers acquire suffictent energy to overcome the activation barrier. According to these arguments, the activation energy related to disorder will decrease, in agreenent with the experimental observations. Thus, for the fibers with more disorder, the probablitty of overcoming the activation barrier increases at high temperatures. According to this conduction mechantsm, the conductivity is expected to be zero at. OK. However In Fig.4, this trend for the behavior of $\sigma(T)$ at lower temperatures is not clearly identifled so that a lower temperature measurement is required to confirm the expected conductivity behavior in the low temperature 1imit. A fit to the $\sigma(T)$ data using these models is discussed further in section IV.

\section{B. Photoconductivity}

In contrast with the intrinsic electrical conductivity, the photoconductivity exhibits a negative temperature dependence for all. the ACFs that were investigated (see Fig.5). This result' is consistent with the lower concentration of intrinsic carriers at low temperatures, thus lowering the recomblnation probability, and increasing the photoconductivity. Also of interest in Fig. 5 is the observation that the fibers with higher surface area also have higher photoconductivities. This fact suggests that the same basic conduction mechanism is operative for the photoconductivity as for the intrinsic conductivity. Namely, the photocarriers are also in localized states and the fibers with more disorder have a smaller hopping range which leads to the higher conduction. Thus the temperature dependent photoconductivity curves in Fig.5 are consistent with the temperature dependent $\sigma(T)$ curves in Fig. 4.

The transient curves for various light intensities all show an exponential rise and fall, as in Fig. 6 where results are shown for the FR15 f tber. Stmilar. values for the rise and decay time of the photoconductance are observed for other fibers. The simple exponential rise and decay curves with no addittonal struccure imply that the energy of the trap states engaged in the clecay process is limited to a narrow energy range around the Fermit level. tf there 
were both shallow and deep trap states involved in the photoconduction process, then the rise and decay curves would constst of two or more parts with different time constants.

The long decay times of about $0.3 \mathrm{sec}$ in Fi.j. 7 indicate that a high density of trap states is involved tn the recombination process because the lifetime of free carriers is generally much shorter, e.g., on the order of $10^{-3}-10^{-8}$ seconds[52]. The long decay times are further not significantly influenced by the magnitude of the speciftc surface area. The observed decay time is usually much longer than the lifetime of free photocarriers because the residence time in trap states is long. In dirordered materials, a high density of trapped states is expected, making the exctted photocarriers rather trumoblle. In fact, a decay time of several seconds was prevtously observed for a deposited carbon f1lm[6]. A similar magnitude of decay time(0.05-0.1sec) was reported for a graphite fiber[53]. Another feature in F.tg.7 is that the decay times are only weakly temperature dependent, with a slight increase in decay time observed with decreasing temperature except for the F'R10 fiber, for which the decay time $1 \mathrm{~s} \simeq 0.3 \mathrm{sec}$.

The kinetics of the reconbination process in the $\Lambda$ CF's is different from that given in a previous report on an evaporated carbon $f 11 \mathrm{~m}[6]$ and a graphite fiber [53] where only the bitrolecular recombination process was observed. The blmolecular recombination process is observed generally when the intrinsic carrier density is small and the photocarrier density becomes dominant(e.g., in insulators)[42]. Figure 8 for the FR15 fiber shows the dependence of photoconductivity on the laser intensity on a log-log scale for vartous temperatures (the other fibers exhibit the same trend). The stgniftcance of this figure is that it shows a change in the recombination kinetics according to the power law dependence for the photoconductivity, $\Delta \sigma \propto \mathrm{P}^{\alpha}$ where $\Delta \sigma$ is the photoconductivity and $\mathrm{P}$ is the incident laser power. If $\alpha=1$, the recombination process is monomolecular, while an exponent $\alpha=0.5$ indicates a bimolecular process. In general., a monomolecular process implies that the density of the intrinsic carriers is much higher than that of photocarriers[42] so that the recombination is limited by the photocarrier density. The inserted triangles 
In Fig.8 indicate the slopes corresponding to the monorolecular and bimolecular processes. In the bimolecular process, recombination is litmited by the avallablitty of photogenerated holes to recomblne with the photoelectrons, so that recombtnation is proportional to the product $A: \Delta \mathrm{p}$ where $\Delta n=\Delta p$. In contrast to the previous result for disordered carbon films[6], Fig.8 clearly shows a monomolecular process $(\alpha=1.0)$ at high temperatures, white the onset of: a blmolecular process $(\alpha=0.5)$ can be seen at low temperatures and at high laser powers. At 290K, the monomolecular process $(\alpha=1.0)$ is dominant at all. laser powers shown. As the temperature is decreased, the s.lope decreases indicating that the bimolecular process $(\alpha=0.5)$ becomes increasingly important and the monomolecular process $(\alpha=1.0)$ becomes less important. A typical case denonstrating the bimolecular process is the regime at $25 \mathrm{~K}$ with the laser power above 4mw, where the slope $1 \mathrm{~s}$ close to 0.5 and the bimolecular process appears to be dominant. Slopes between 0.5 and 1.0 are observed for most of the data at $\simeq 100 \mathrm{~K}$, suggesting that the contribution of the monomolecular process is comparable to that of the bimolecular process. This trend that the bimolecular process becomes dominant at low temperatures and at high laser powers is reasonable because the denstty of photocarrters becomes dominant relative to the intrinstc carrier density under those conditions.

Figure 9 shows more clearly the change in recombination ktnetilcs. In this figure, the power (In $\Delta \sigma=\Lambda P \alpha)$ is plotted versus the laser power $P$ at each temperature, where $\Lambda$ is a constant. In our experiments, the monomolecular process $(\alpha=1.0)$ was observed at hitgh temperatures. 'Ihis is consistent with the fact that the intrinsio conductivity j.s much larger than the photoconductivity at high temperatures. On the other hand, at low temperatures where the photoconductivity is comparable to the intrinsic conductivity, the power approaches $\simeq 0.5$. Thi.s phenomenon suggests that the dominant carriers in the material are photocarriers at low temperatures, and as a result the main recombination process occurs between the photocarriers (1.e., between the photoelectrons and photoholes). In our experiments, both types of recombination kinetics were observed (see Flg.9) since the relative dominance 
of the intrinsic carrier concentration and of the photocarriers could be reversed, depending on the cholce of incident laser power and on the temperature.

The magnitides of the dependence on laser power of the photoconductivity $\sigma(T)$ relative to room temperature are shown in Ftg.10(for the IR15 fiber) for three different temperatures. Thits figure indicates that the dependence on laser power becomes smaller with increasing temperature. If the data are extrapolated to high laser power levels, the temperature-dependence would disappear at around $100 \mathrm{~mW}$. At $100 \mathrm{~mW}$ where the photoconductivity is essentially temperature-independent, the denstty of intrinsic carrders is negligible compared to the photocarrters induced at that power level. $\left(\simeq 10^{15}\right.$ photons/sec per fiber). In contrast, at low laser powers where the denstty of the induced photocarriers is smal1, the photoconductivity is rather temperature-dependent.

We note that the observed increase in conductivity during the laser pulse is not caused by a heating effect. If a heating effect caused the increase in conductivity, changes in the recombination kinetics would not be observed. Furthermore, a temperature rise caused by a heating effect: would produce an almost temperature-independent increase tn the conductivity. Because the do/dT is nearly constant as seen In Fig.4, a constant conductivity deviation would be observed, provided that the temperature rise by the laser incident is near constant over the studier temperatures. However in fact, the experiments show that the conductivities (Fig.5) change by a factor of several over the temperature range $30-290 \mathrm{~K}$. For these reasons, we believe that the effect is not a heating effect but rather a photoeffect. However, it may be difficult to distinguish a heating effect from a photoeffect if the heat exchange process occurs on the same time scale as the photocarrier recombination process.

\section{Discusston}

We have fit the temperature-dependent conductivity data to investigate the intrinsic conduction mechanisms. Figure 11 shows the fit of a model where two 
terms are assumed, a constant terit and a temperature dependent term, 1.e., $\sigma=\sigma_{\text {hop }}+\sigma_{\text {act }}$. The first term $\sigma_{\text {hop }}$ is associated with the variable range hopping process, but appears to be temperature indep nndent above $\simeq 30 \mathrm{~K}$ for the ACFs studied in the present work. The temperature dependent term $\sigma_{\text {act }}\left(=\sigma_{\text {act }}^{\circ} \exp (-\mathrm{E} / \mathrm{kT})\right)$ is written as a simple activation term. The fits for the various fibers to this functional form are shown in Fig.11 and values for $\sigma_{\text {hop and }} \sigma_{\text {act }}$ are given in Table 3. The term due to the hopping conduction ( $\sigma_{\text {hop }}$ ) is found to increase strongly with increasing specific surface area(SSA), though we have not been able to ind the functional dependence of $\sigma_{\text {hop }}$ on SSA. The temperature-dependence of the intrinsic conductivity then comes from the temperature-dependent term ( $\sigma_{\text {act}}$ ) based on a thermal activation process. From the fits in Fig.11 we see that the activation energy $\mathrm{E}$ decreases with increasing SSA, but because of the exponential dependence on $E$, the effect of increasing the SSA is quite large. The net effect is that the temperature dependent term increases more rapidly with SSA than $\sigma_{\text {hop }}$ For example, the magnitude of $\sigma_{\text {hop }}$ at room temperature is only 15-25\% of $\sigma_{\text {act }}$ for a.l the fibers. At high temperatures, satisfactory agreenent between the data and the model is shown in Fig.11, although the fit is not good at low temperatures. In terms of the prefactor $\sigma^{\circ}$ act of the thermal activation term $\sigma_{\text {act, }}$ an increase (from 23.0 to $45.6 \mathrm{~S} / \mathrm{cm}$ ) with SSA (from 1000 to $2000 \mathrm{~m}^{2} / \mathrm{g}$ ) is nuserved. Since the prefactor becomes large as the inelastic collision length decreases[51], this trend for the prefactors is reasonable. From the magnitudes of the prefactors, an approximate inelastic collision length is estimated to be 15-30A, following the equation[51] that the prefactor is about $0.03 e^{2} / \mathrm{hI}_{1}$ where $\mathrm{L}_{i}$ is a inelastic collision length. However, we could not distinguish whether this activation process is based on a nearest hopping of carriexs or c n a simple activation of trapped carriers to excited states because these two functions have the same form of $\exp (-\mathrm{E} / \mathrm{kT})$.

With regard to the mechanism for the increase in the photoconductivity at low temperatures(Fig.5), an increase in the photocarrier concentration based on a increase in the lifetime is required. There are two explanations for the 
increase in the 1ifetime. One explanation is that a decrease in the mobility of the photocarriers at low temperatures leads to a lower recombination rate, resulting the longer lifetime. If carriers are less mobile, the probability for carriers to meet each other and to recombine is reduced. In this model all the carriers of the appropriate sign are assumed to be equally involved in the recombination process. The other explanation is that themally excited intrinsic carriers play a main role in the recombination process. In this model specific mobile carriers control the recombination process. Because the concentration of these excited carriers is temperature dependent, the decrease in the concentration of these carriers at low temperatures leads to a lower recombination rate, resulting in a longer lifetime of the photocarriers. It is difficult to specify here which mechanism is dominant. It depends on whether the states of the carriers in this disordered carbon are all lccalized or whether they have some extended states.

At low temperatures, the density of photocarriers is expected to become very large because of their long lifetime. The photoconductivity, however, is expected to show a decrease as the temperature is lowered further because the carriers become more immobile, and because the density of photocarriers eventually reaches a finite value depending on the laser power. In fact, the FR10 fiber shows a saturation effect below 50K in Fig.5. This idea predicts that the photoconductivity and the intrinsic conductivity will eventually become zero at $\mathrm{OK}$.

Assuming an appropriate value of the mobility, it is possible to estimate the densities of the intrinsic carriers and of the photocarriers. For the mobllity in the localized states, $1 \mathrm{~cm}^{2} /$ vsec is assumed based on the calculated mobility of a phenol resin [54] for which the conductivity and the heat treatment temperature were about the same as for the ACF's in this work. 'Ihen the density of the intrinsic carriers and of the photocarriers at room temperature are estimated to be $\simeq 1021 / \mathrm{cm}^{3}$ and $\simeq 1020 / \mathrm{cm}^{3}$ (in case of $10 \mathrm{mw}$ laser power), respectively, assuming the majority of carriers exist in trapped states. This magnitude of the intrinsic carrier density is comparable to the 
value of around $10^{20} / \mathrm{cm}^{3}$ obtained by the Hall measurements and ESR[54] of a phenol resin. These values are also reasonable because Fig.10 indicates that about $100 \mathrm{mw}$ of incident light would generate a higher photocarrier density than the intrinsic carriers.

\section{Conclustons}

Measurements of the intrinsic conductivity and the photoconductivity of activated carbon fibers have been carried out over the temperature range 30$290 \mathrm{~K}$. The temperature dependence is positive for the intrinsic conductivity and negative for the photoconductivity. The decay time of the photoconductivity is about $0.3 \mathrm{sec}$. The recombination kinetics change from a monomolecular process to a bimolecular process with decreasing temperature and increasing photon intensity. It is assumed that most intrinsic carriers and photocarriers exist in a high density of localized states in this material. The main conduction mechanism is assumed to be variable range hopping at low temperatures and at high temperatures either short range hopping or thermal activation of carriers. An activation energy of about 20 mev for the tempersiture-dependent term in the intrinsic conductivity fits the experimental data well at high temperatures. The density of the intrinsic carriers and the photocarriers at room temperature are estimated to be $\simeq 10^{21} / \mathrm{cm}^{3}$ and $\simeq 10^{20} / \mathrm{cm}^{3}$ (in the case of $10 \mathrm{mw}$ laser power), respectively. Both the intrinsic conductivity and the photoconductivity are expected to approach zero as $\mathrm{T}+0 \mathrm{~K}$. We have found that photoconductivity measurements, in combination with conductivity measurements, provide valuable information for understanding of the electronic properties of disordered carbon materials.

\section{Acknowledgments}

We would like to thank Dr.G.Dresselhaus, Professor M. Endo for enlightening conversations, Dr.A.Rao for help with the experiments, and A.Fung and S.divittorio for both. We gratefully acknowledge support from Sumitomo Metal Industries(K.K) and Lawrence Livermore Laboratory Subcontract \#B1305.30(M.S.D). 
+permanent Address: Advanced Carbon Research Laboratory, Sumitomo Metal
Industries Ltd., Sunayana 16, llasak1, Kashima, Ibaraki-ken, Japan

References

1. J.R.Dacey, D.F.Quinn and J.T.Gallagher, Carbon 4, (1966) 73

2. R.McIntosh, R.S.Halnes and G.C.Benson, J. Cherll. Phys. 15, (1947)17

3. W.W.Smeltzer and R.Mc.Intosh, Cann. J. Chern. 31, (1953)1239

4. M.D.Blue and G.G.Danielson, J.Appl.Phys. 28,(1957) 583

5. T. Hanawa and J.Kakinoki, Carbon 1, (1954) 403

6. J.M.MacFarlane, I.S.McLintock and J.C.Orr, Phys. Stat. Sol.(a)3,(1970)K239

7. S.Mizushima and Y.H.trabayash1, Carbon 6, (1968)123

8. I.S.Mclintock aná J.C.Orr, Carbon 6, (1968) 309

9. V.R.Deitz and E.F.MacFarlane, Proceedings of the Fifth Carbon Conference, Vo1.2, p219, Pergamon Press, Oxford (1963)

10. I.S.Mclintock and J.C.Orr, Carbon 5, (1967) 291

11. H.H1rabayashi and H.Toyoda, Proceedings of the Fourth Carbon Conference, p227, Pergamion Press, Oxford (1961)

12. F.Carmona, P.Delhaes, G.Keryer and J.P.Manceau, Solid State Communi.14, (1974) 1.183

13. R.R.Saxena and R.H.Bragg, J. Non-Cryst. Soltd 28,(1978) 45

14. D.F.Baker and R.H.Bragg, Phys. Rev. B 28,4, (1983) 2219

15. J.W.Armstrong, C.Lackson and H.Marsh, Carbon 2, (1964) 239

16. B.D.McMichael, E.A.Kmetko and S.Mrozowski, J. Optical Society of America $44,1,(1954) 26$

17. P.L.Walker, L.G.Austin and J.J.Tietjen, Carbon 2, (1965)1710

18. Y.Maruyama and H.Inokucht, Chem. Soc. of Jap. Bu11. 39, 7, (1966)1418

19. E.A.Davis and R.F.Shaw, J. Non-Cryst. Solid 2, (1970) 406

20. W. Biicker, J. Non-Cryst. Soltd 12, (1973) 115

21. S.Mrozowsk1, Phys. Rev. 77, (1950)838

22. S.Mrozowski, Carbon 3, (1965) 305

23. S.Mrozowski, Carbon 6, (1968) 841 
24. S.Mrozowski, Phys. Rev. 85, (1952)609

25. S.Mrozowsk1, Carbon 9, (1971)97

26. S.Mrozowskt., Carbon 11, (1973)433

27. S.Mrozowskt, J. Low Ternp. Phys. 35, (1979) 231

23. H.Nagata and '1.Yoshida, Chenical Economics, (1977 npri1)44

29. S.Ikegami and K. Shirazak1, Fusl and Combustion 54, 2 (1987)

30. N.Ishizaki, Chemlcal Engineerting (1984 July) 24

31. K.Tai and N.Shishtdo, Polymer processing 35; (1986) 384

32. G.N.Arons and R.N.Macnair, Text1le Res. J. 42, (1972)60

33. E.Tanaka, Fuel and Combustion 54, 4, (1987)241

34. A. Yoshida, I.Tanahashd, Y.Takeuch and A.Nishino, IEEE CHMI-10,1, (1987) 100

35. N.Kasaoka, Y.Sakata, E.Tanaka and R.Naito, J. Chem. Soc. Japan, (1987) 990

36. G.M.Nieh and D.T.Grow, J. Collold Interface Sclence 119, 1, (1987)280

37. J.W.Herrick, in "23rd Ann. Tech. Conf.SPI Reinforced Plastics/Composites, $16 A(1968)$

38. Y.Kom tsubara, S.Ida, H.Fujitsu and I.Mochida, Fuel. 63, (1984)1738

39. I.Mochida, M.Ogak1, H.Fujttsu, Y.Konatsubara and S.Ida, Fuel. 64, (1985) 1054

40. G.G.Jayson, T.A.Lrawless and D.J.F'aitrhurst, J. Collold and Interface Science 86, (1982) 379

41. K.Kaneko and N1.Shindo, Carbon 27, 6, (1989)815

42. R.H.Bube, Phintoconductivity of Solids, W.ley, New York, London, 1960

43. A.Rose, Concepts in Photoconduct.tity and Allied Problems, Interscience Publtshers, New York, 1963

44. Photoconductivdty and Related Phenomena, J.Mort and D.M.Pat edit, Elsevier, 1976

45. S.Mrozowski and A.Chaberski, Phys. Rev. 104, (1956) 74

46. C.A.Klein, J. Applied Physics 35, 10, (1964) 2947

47. P.Delhaes and F.Carmona, Physical properties of non-crystalline carbons, Chem. Phys. Carbon 17 (1981)

48. S.divittorto et al., unpublished

49. J.Heremans, Carbon 23,4,(1985) 431 
50. I.L.Spatn, K.J.Volin, H.A.Goldberg and I.Kalntn, J. Phys. Chem. Sollds 44, 8, (1983) 839

51. N.Mott, "Conduction in Non-Crystalilne Materials", Oxford University Press (1987)

52. N.W.Ashcroft and N.D.Mermin, "Solid state Physics", Holt, Rinehart \& winston(1976)

53. J.Steinbeck, G.Braunstein, M.S.Dresselhaus, G.Dresselhaus and T.Venkatesan, Extended Abstracts of Symposium $\mathrm{K}$ "Graphite Intercalation Conpounds", 1986 Fall. Meeting of the MRS, p129

54. W.Bücker, J. Non-Cryst. Solid 18, (1975)11 


\section{Figure Captions}

Fig.1 Gemetry of the $\mathrm{ACF}$ sample mounted on a mica substrate. The laser bearn $10 \mathrm{~mW} \mathrm{Ar}^{+}$ton laser trradtates the tridtcated ctrcular regton(see inset) and $\simeq 10^{14}$ photons/sec are inctdent on the fiber.

Fitg.2 Scanning Electron Mtcroscopy photographs of a phenol-dertved $\Lambda C F$. (a)cross section of a fiber, having a rather round shape and a snooth surfice. (b)cross section with a higher magnification. The witch of the crack-1.ke openings is $\simeq 500 \AA$. The length scales in both photogiaphs are gitven.

Fig. 3 X-ray diffraction pattern of $\Lambda C F(F R 12)$.

Fig.4 Temperature dependence of the "intrinsic" electrical conductivity for the four types of fibers.

Fig.5 Temperature dependence of the photoconductivity for each of the fiber types.

Fig.6 Decay time of the finduced photoconductivity for each of the four types of fibers as a function of temperature.

Fig.7 Decay curves of photoconductivity at the incident laser powers of 10,4 and $1 \mathrm{~mW}$ at $30 \mathrm{~K}$.

Fig. 8 photoconductivity dependence on irradiation power at vartous: temperatures for the FR15 fuber, plotted on a log-log scale.

FIg.9 Change in recomblnation kinetics at vartous incitent power level. $\alpha=1$ and 0.5 tmplies a monomolecular process or a bimolecular frocess, respect tvely. 
Fig.10 Change in the temperature dependence of the photoconductivity as a function of power level. An extrapolation to the high power 1.tmit tndicates that the temperature dependence disappears(the ratio becomes undty for all. temperatures showri) at $100 \mathrm{mw}$.

Fig. 11 Calculation of the "intrinstc" conductivttes based on a conduction modeh. "The insert indicates the conduction moclel. schematically. The mrodel consists of two terms based on a thermal activation process (o act) and a hoppling process ( o hop). 'The hopping process ts almost constrant over the studled temperature range.

t'able 1. Properties of phenol--dertved activated carbon fibers

'Table 2. Conduct.tvity values for vartous ditsordered carbons

Table 3. Fitting values for the conductivity 


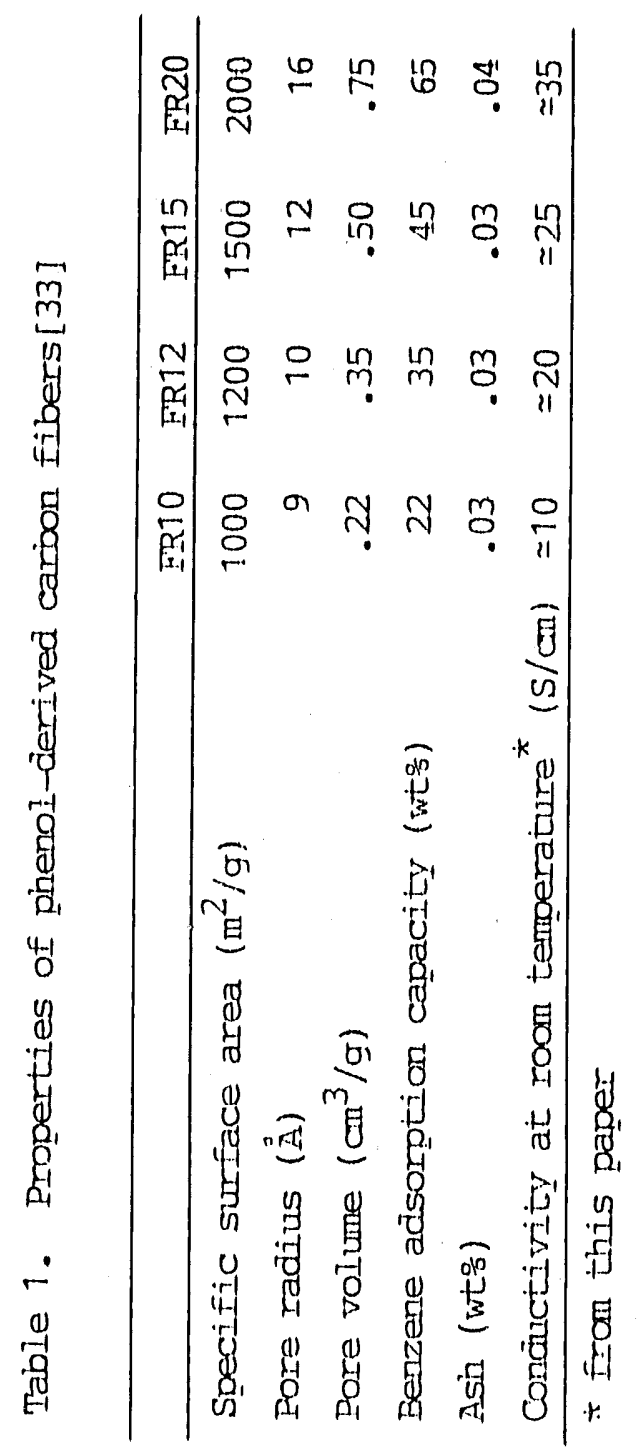




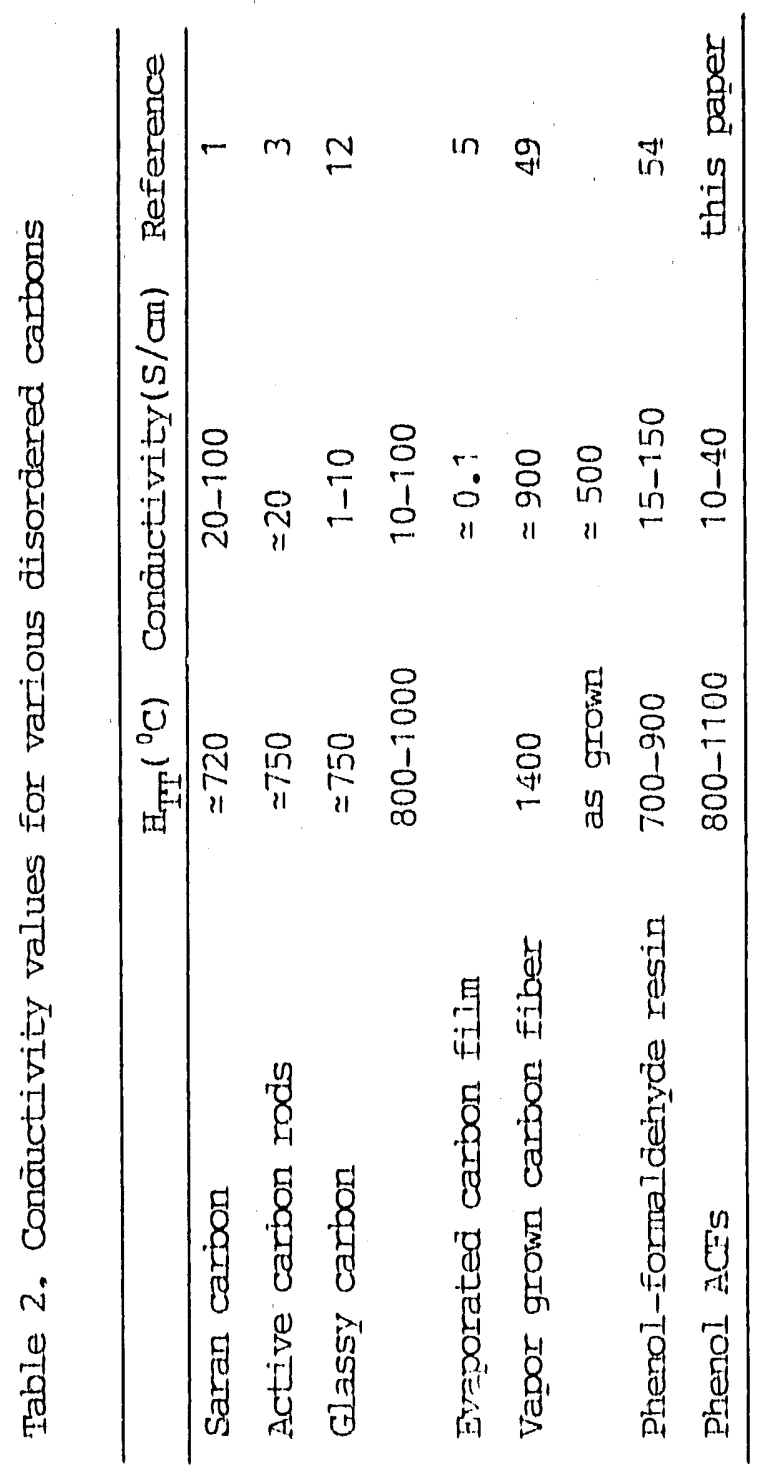


Table 3. Fitting values for the conductivity ${ }^{*}$

\begin{tabular}{lccc}
\hline & $\sigma_{\text {hop }}(\mathrm{S} / \mathrm{cm})$ & \multicolumn{2}{c}{$\sigma_{\mathrm{act}}(\mathrm{S} / \mathrm{cmi})$} \\
& & $\sigma_{\text {act }}^{0}(\mathrm{~S} / \mathrm{cm})$ & $\mathrm{E}(\mathrm{mrV})$ \\
\hline FR10 & 2.2 & 37.0 & 24 \\
FR12 & 5.6 & 39.6 & 22 \\
FR15 & 7.9 & 45.6 & 19 \\
FR20 & 10.3 & & \\
\hline * f1ttIng equation $1 \mathrm{~s}$ \\
$\sigma(\mathrm{T})=\sigma_{\text {hop }}+\sigma_{\text {act }}=\sigma_{\text {hop }}+\sigma_{\text {act }}^{0} \exp \left(-\mathrm{E} / \mathrm{K}^{\prime} \mathrm{I}^{\prime}\right)$
\end{tabular}




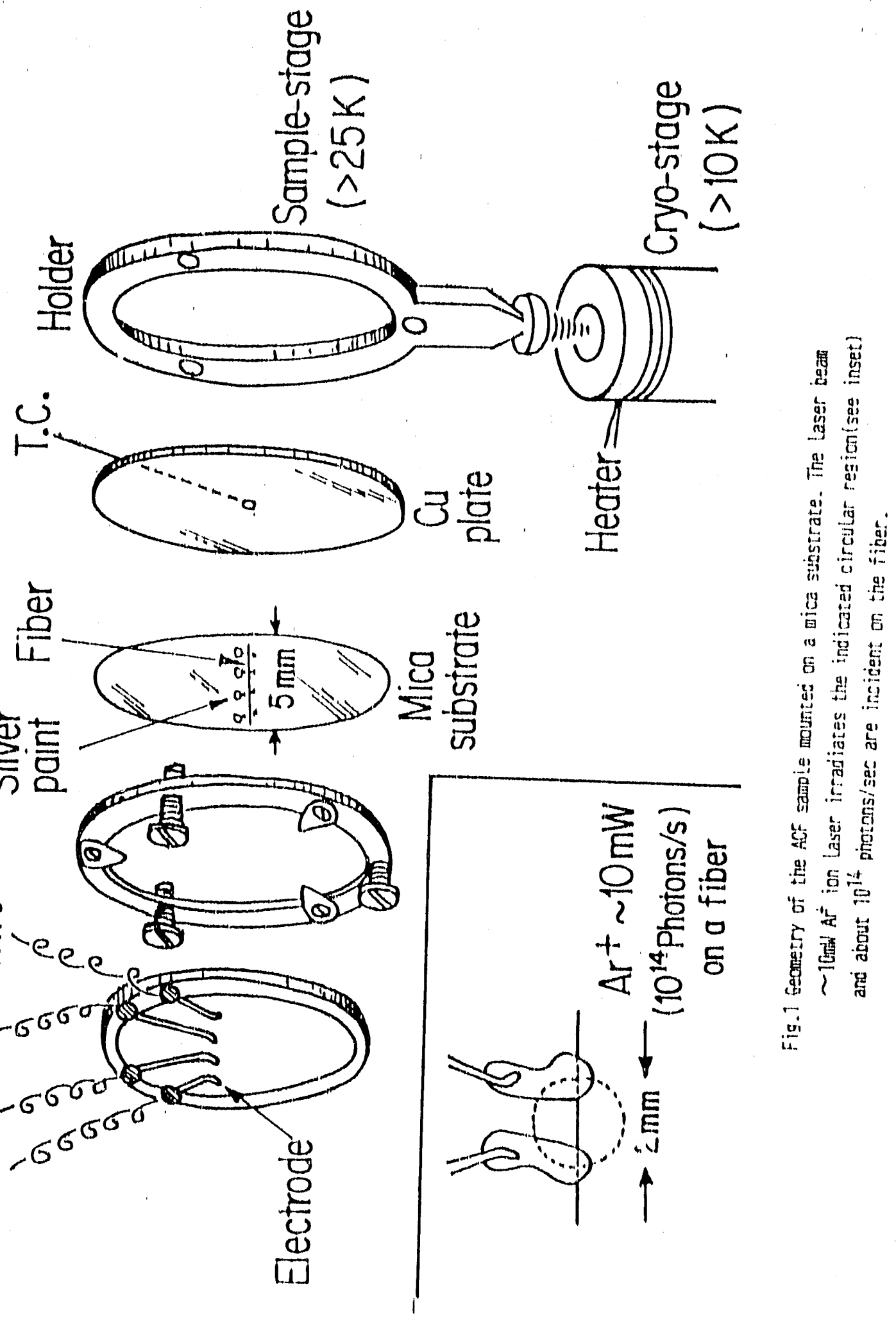



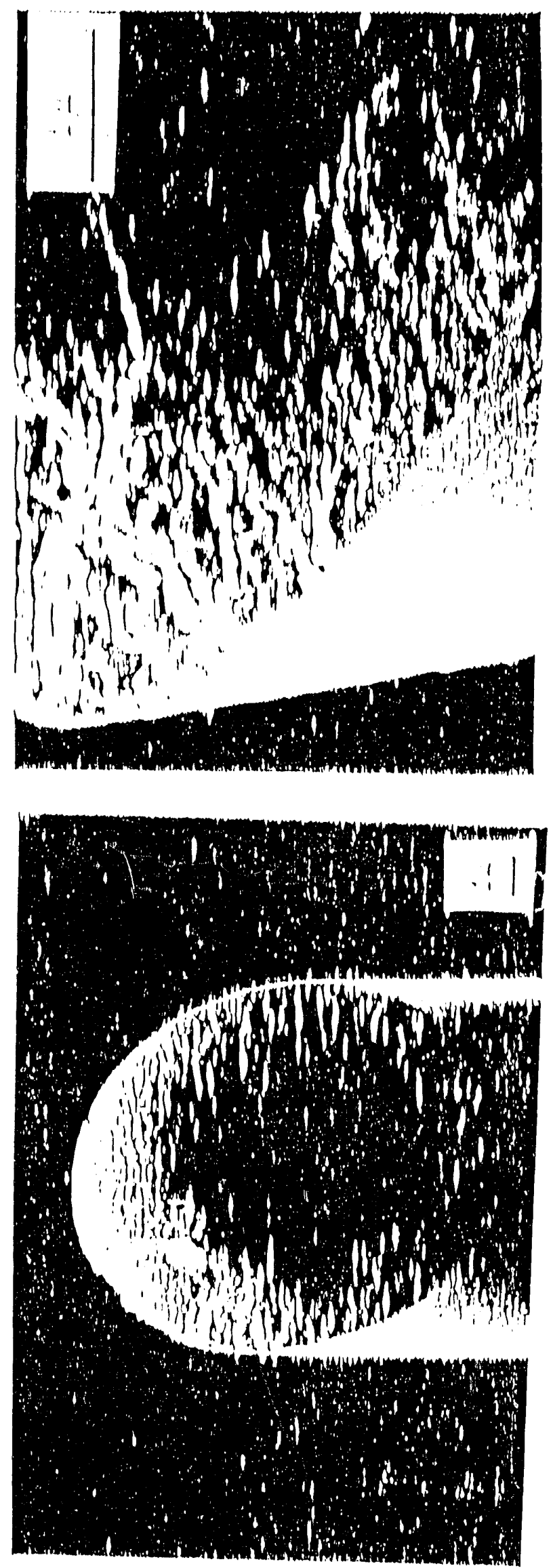


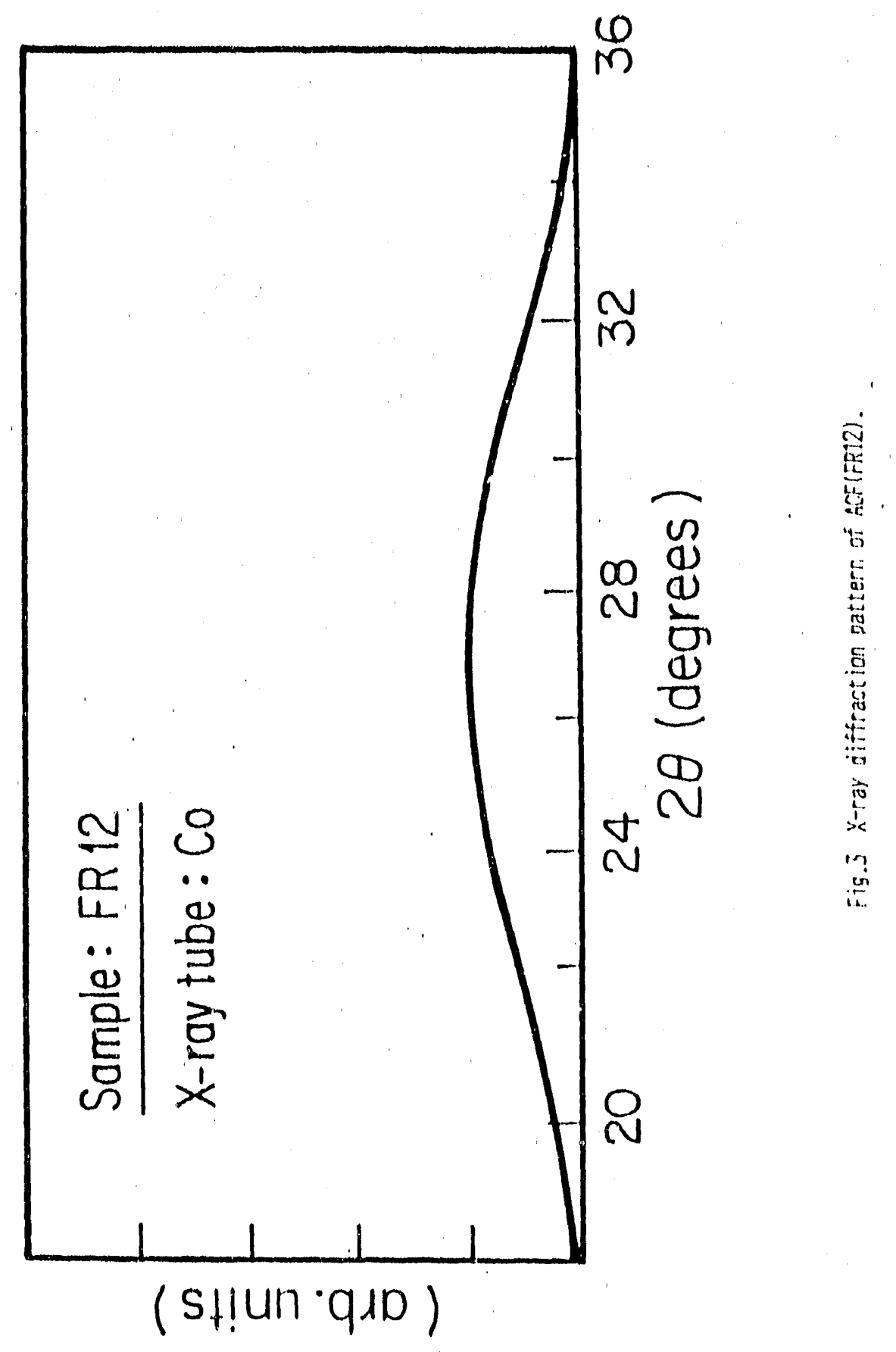




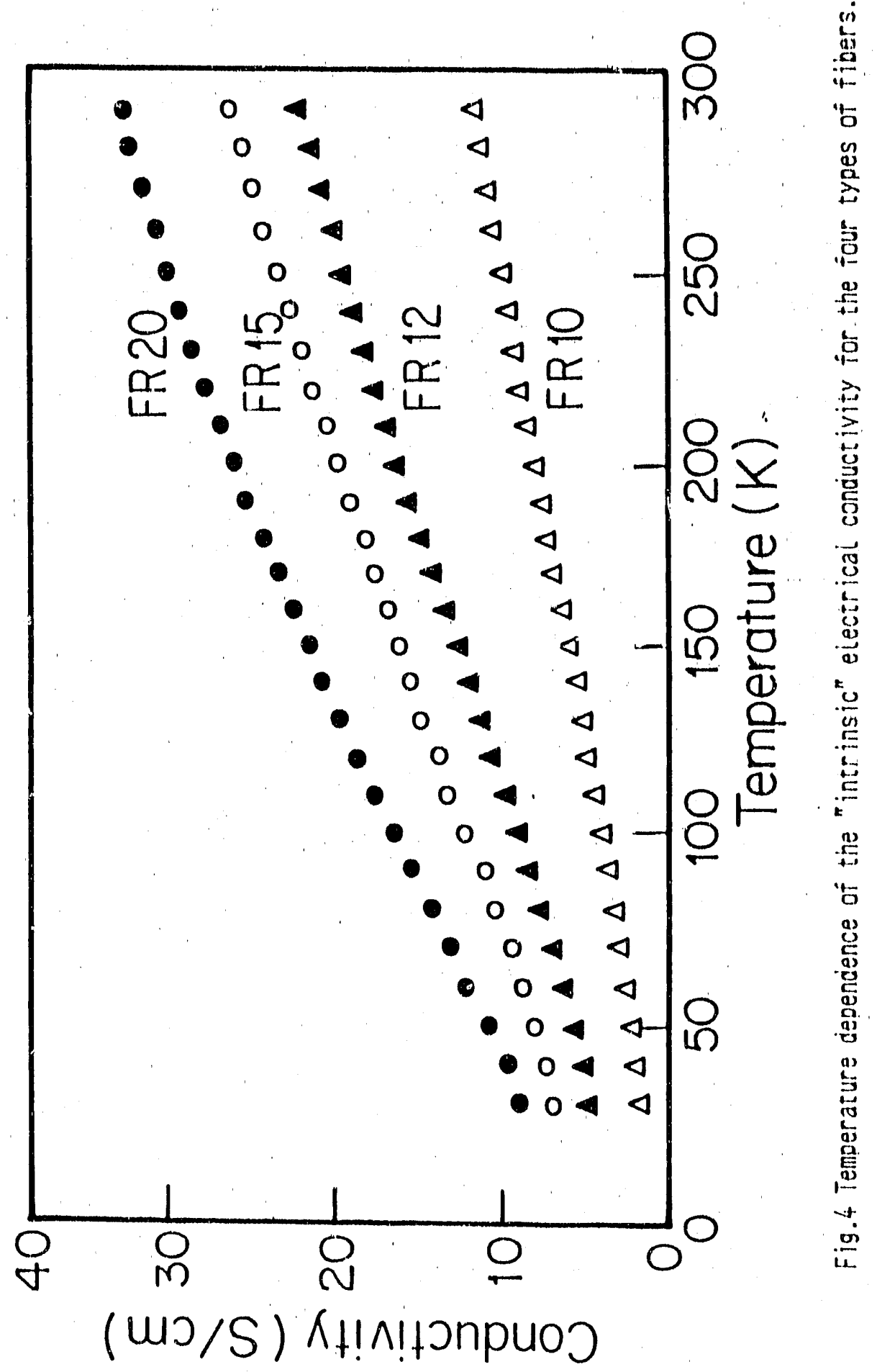




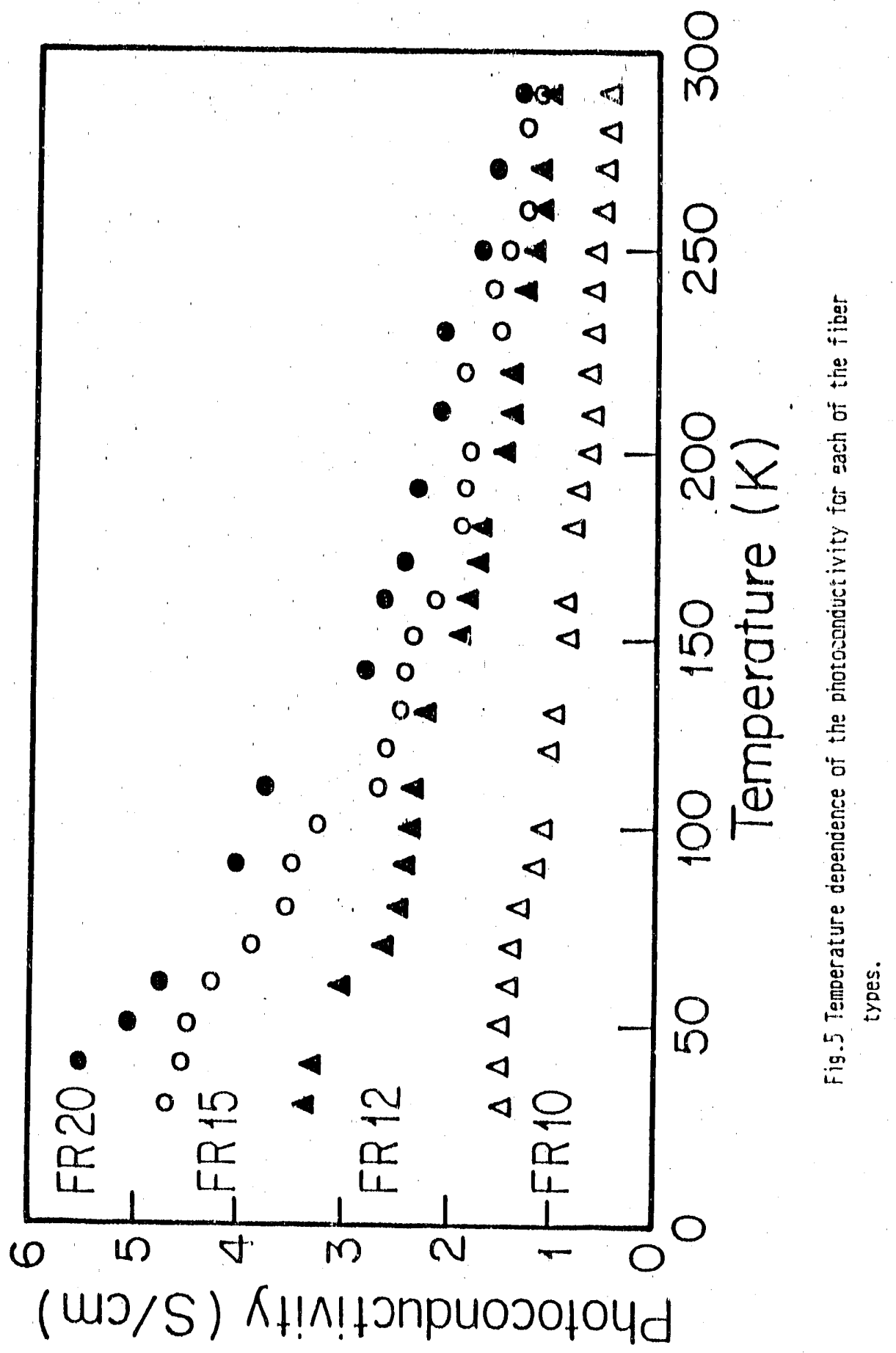




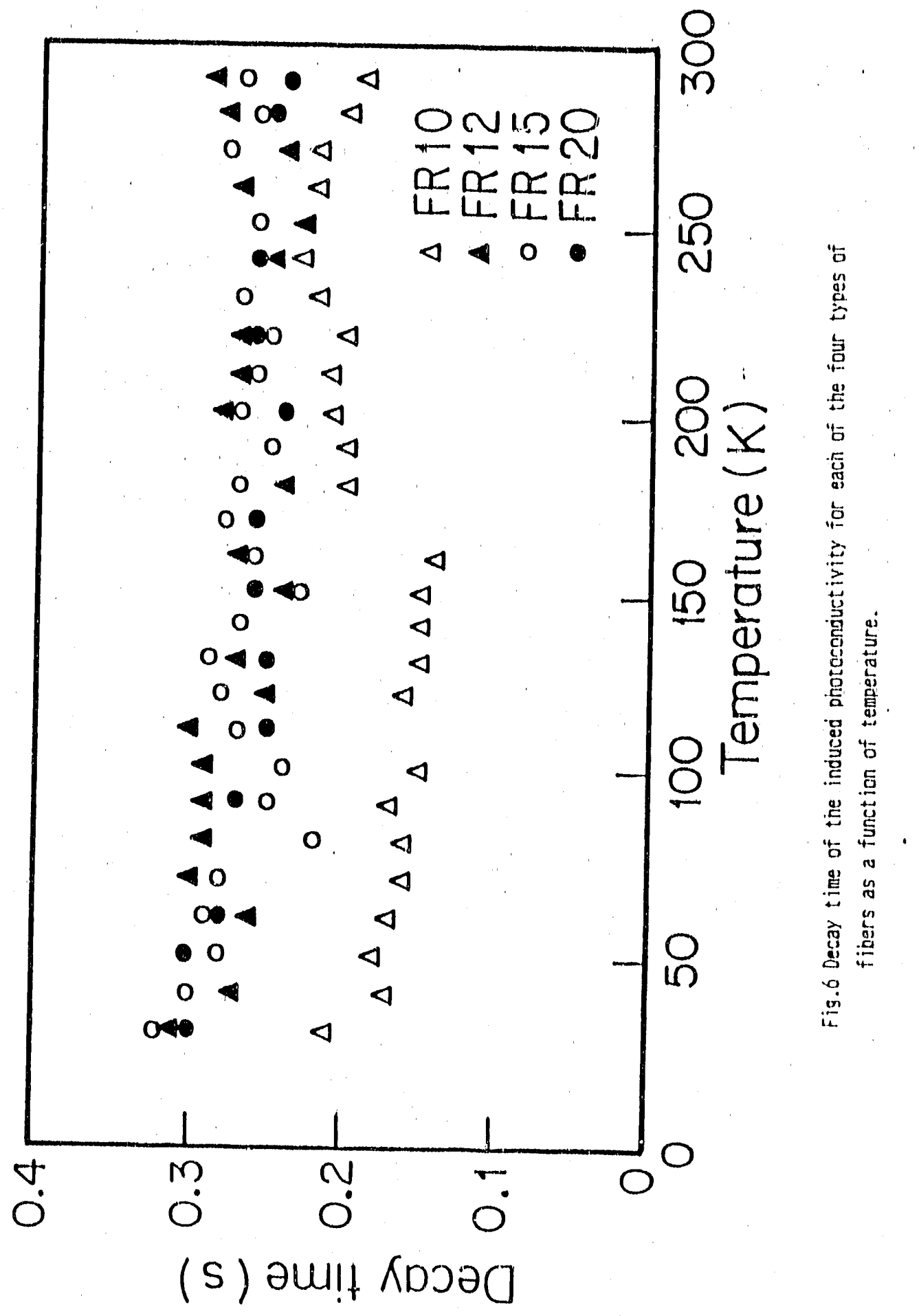




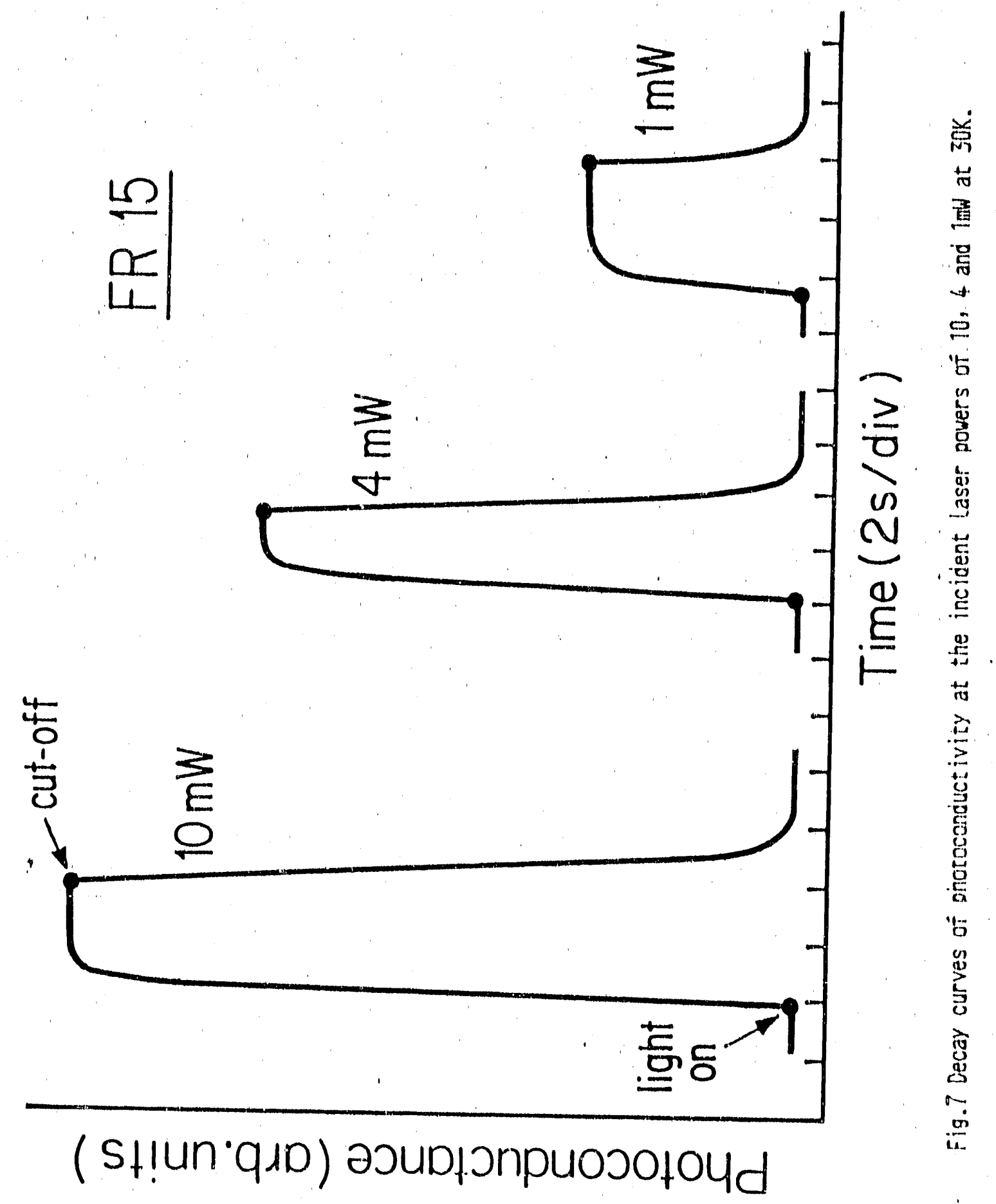




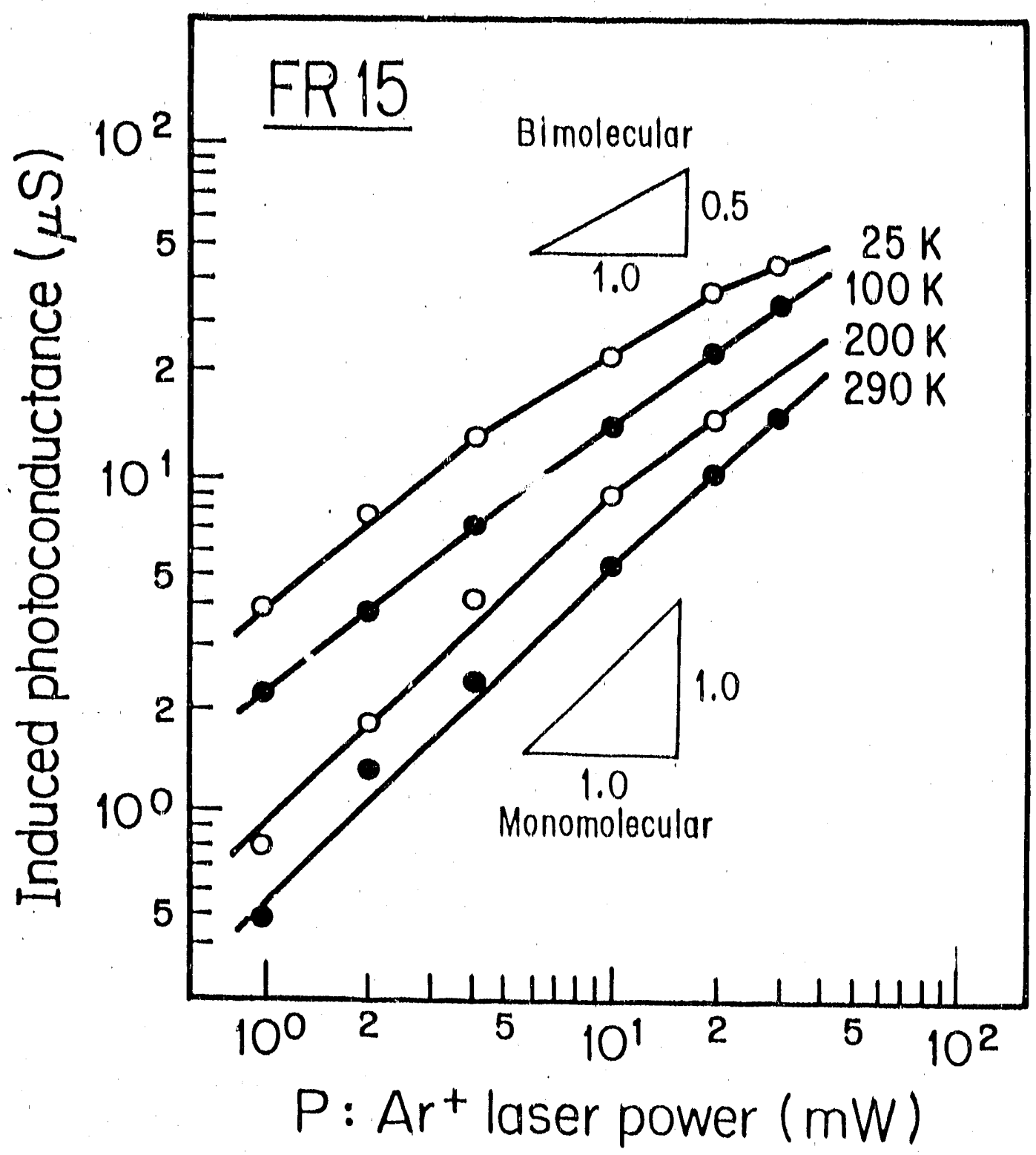

Fig. 8 Photocanductivity dependence on Irradlation power at varlous temperatures for the FR15 flber, plotted on a $\log -\log$ scale. 


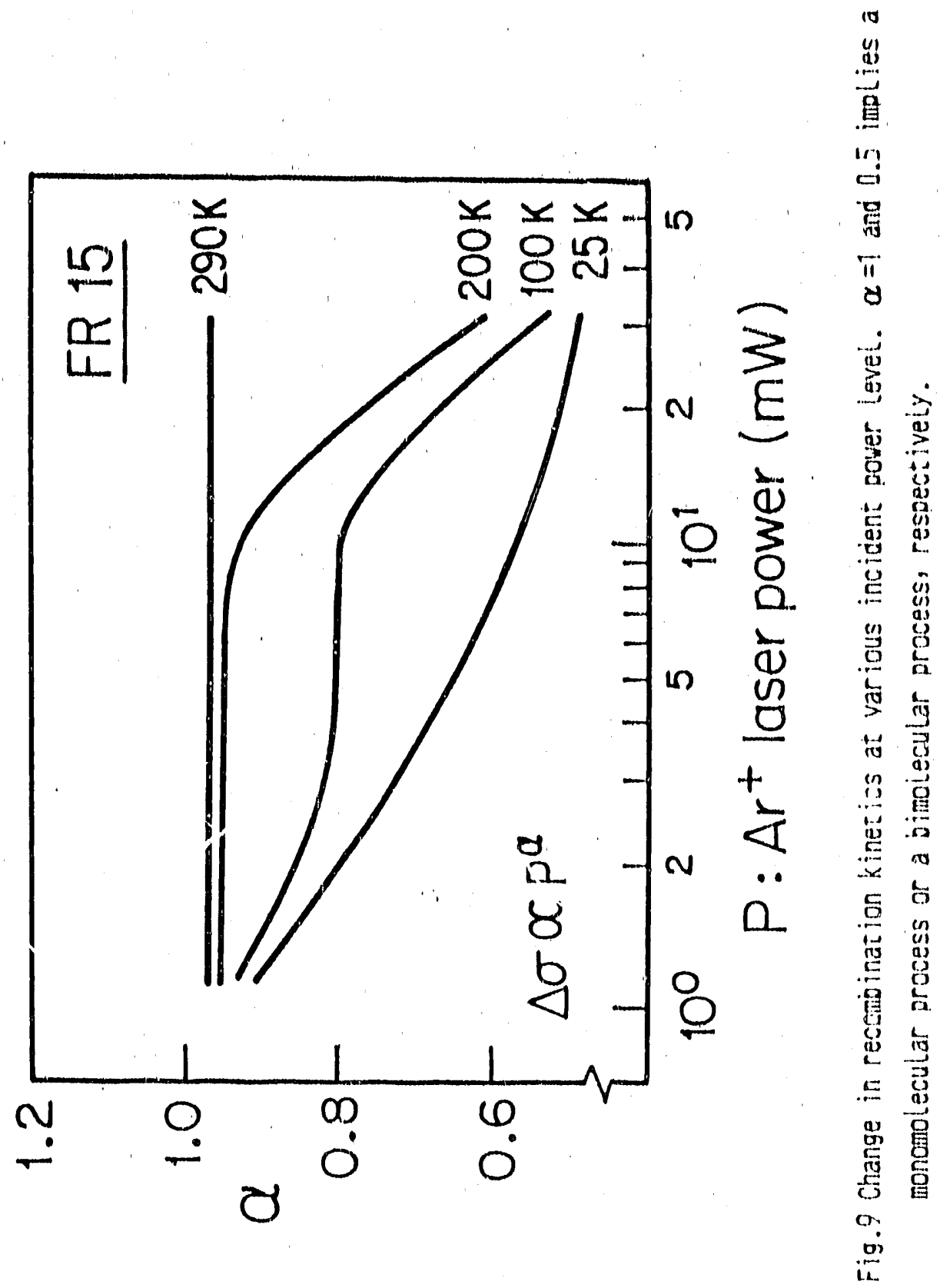



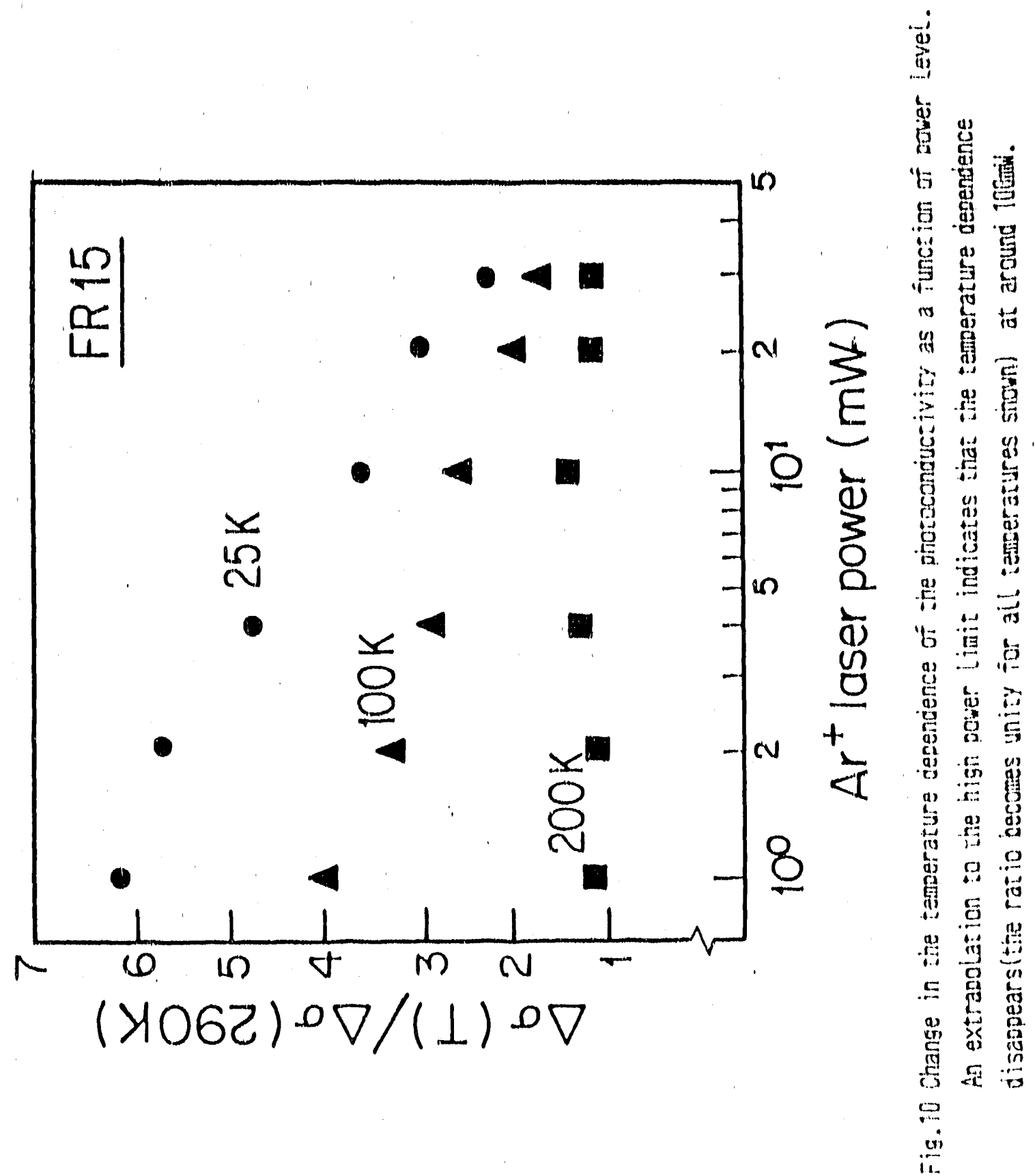


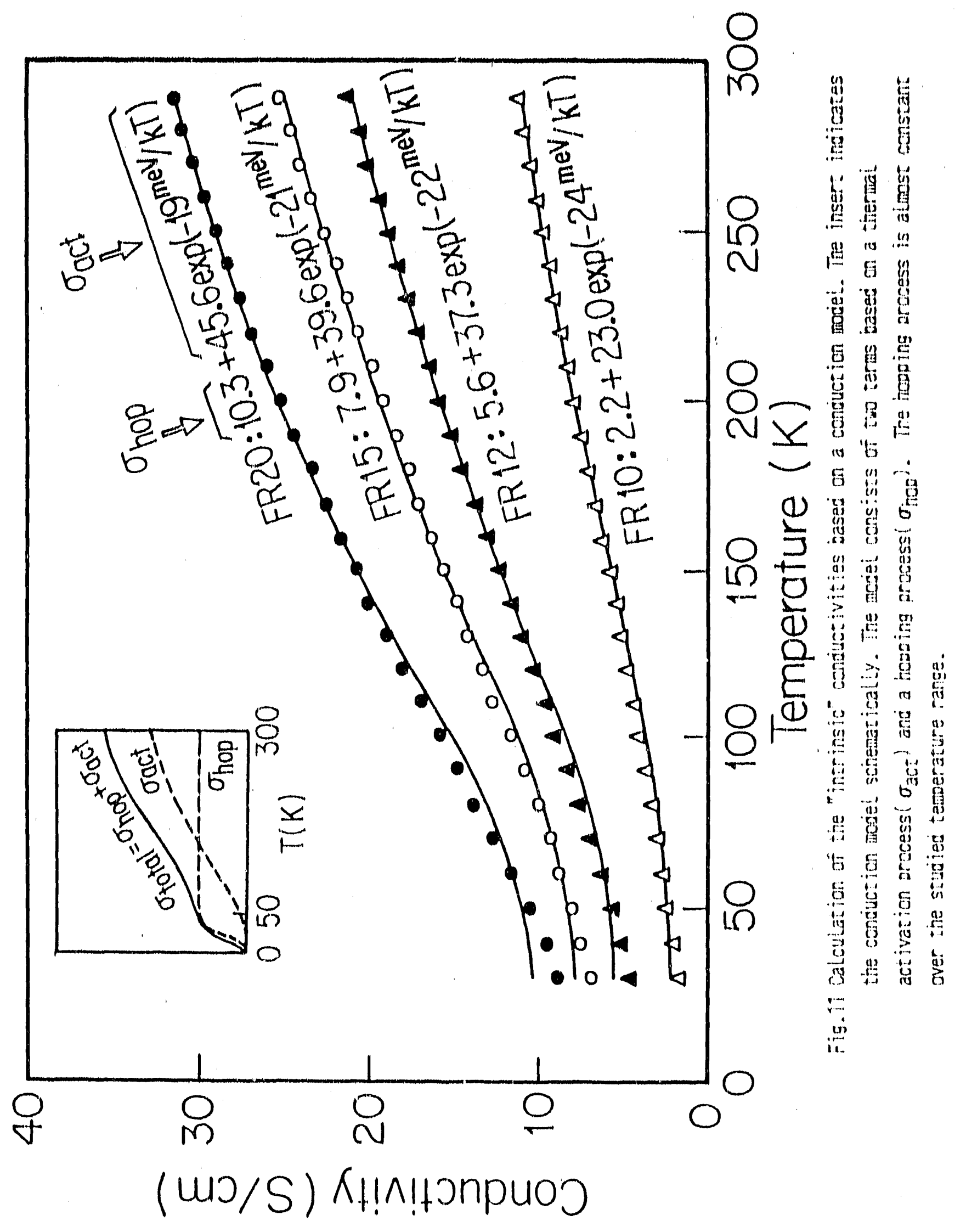


| 